\title{
CARACTERIZAÇÃO ANATÔMICA DA MADEIRA \\ DE Grevillea robusta A. Cunn.
}

Silvana Nisgoski

Mestranda em Engenharia Florestal - UFPR

Graciela I. B. de Muñiz e Umberto Klock

Departamento de Engenharia e Tecnologia Rurais

UFPR - Curitiba, PR

\section{RESUMO}

O presente trabalho trata da descrição dos caracteres gerais e microscópicos da madeira de Grevillea robusta A. Cunn, sendo fornecidas fotomicrografias e fotografias em microscópio eletrônico. Foram encontrados poros múltiplos radiais e tangenciais, associados às faixas de parênquima, formando festões entre os raios; raios homogêneos a fracamente heterogêneos, uni e multisseriados; fibras libriformes não septadas; canais intercelulares radiais e máculas medulares ocasionais. Os elementos constituintes foram avaliados em relação à posição dentro da árvore (base e topo) e dentro do disco (próximo à casca e próximo à medula).

\section{SUMMARY}

The wood anatomy of Grevillea robusta A. Cunn is described. Photomicrographs e photographs in electronic microscope are furnished. Vessels typically in tangential pairs and groups. Parenchyma typically as 
narrow to wide bands curving inwards between the large rays. Rays of two distinct sizes, usually homogeneous except for occasional sheath cells. Libriform fibers and not septate. Traumatic vertical intercellular canals occasionally present. Stain pith occasionally were found. The constituent elements were analyzed in function of tree position.

\section{INTRODUÇÃO}

As espécies da subdivisão Angiospermae, vêm adquirindo progressiva importância industrial, mercê do avanço tecnológico das últimas décadas. Os estudos são induzidos pela diminuição do estoque disponível de coníferas ou pela necessidade de aproveitamento mais racional de folhosas economicamente promissoras, revelando características notáveis e específicas dessas essências.

As experiências com reflorestamentos de outras espécies, nativas ou exóticas, e que podem produzir madeiras especiais, são ainda incipientes, sendo necessários estudos no que diz respeito às propriedades anatômicas, físicas e mecânicas, para que as exigências de cada usuário, seja em termos de resistência, trabalhabilidade ou simplesmente no aspecto decorativo, possam ser atendidas.

Segundo PIO CORRÊA (1978), a Grevillea robusta é uma espécie rústica originária da Austrália e muito elegante, achando-se perfeitamente aclimatada ao Brasil, resistindo às secas e geadas, aceitando qualquer tipo de terreno desde que não sejam úmidos, até mesmo os calcáreos, quando secos ou bem drenados. Desta facilidade de adaptação temos a prova no fato de ser hoje, pelo menos no sul do Brasil, uma das espécies mais vulgarizadas e apreciadas para arborização de ruas e praças, além de largamente empregada pelos particulares, até mesmo como um bom quebra-vento.

Árvore grande atingindo até $30 \mathrm{~m}$ de altura; ramos novos esbranquiçados e tomentosos; folhas bipinatífidas com até $90 \mathrm{~cm}$ de 
comprimento e $35 \mathrm{~cm}$ de largura, compostas por 11 a 21 folíolos estreitos, lanceolados, agudo-atenuados, fendidos, às vezes inteiros, glabros na parte superior e sedosos ou canescentes na parte inferior, sendo os últimos menores; flores vermelho amarelas ou amarelo alaranjadas, dispostas em racemos cilíndricos, axilares e terminais, de 7 a $18 \mathrm{~cm}$, semi-eretos, densifloros, paniculados; fruto folículo ovóide, oblíquo recurvado, subcomprimido, apiculado; sementes obovóides, sub-aladas, comprimidas (PIO CORRÊA, 1978).

Fornece madeira de cor castanho claro a castanho rosado, macia, acetinada, lustrosa, elástica, raios medulares largos e bem definidos; poros longos porém em número reduzido, alguns fechados, tendo em conjunto o aspecto da madeira do carvalho europeu. Muito decorativa e própria para obras internas, taboado de assoalho e de forro, marcenaria, carpintaria e lenha. Peso específico $0,564 \mathrm{~g} / \mathrm{cm}^{3}$. Serrada em tábuas seca com facilidade e rapidez, sendo possível aproveitar o material poucos meses depois de abatida a árvore. Como melífera é espécie preciosa para a apicultura. A casca exsuda uma goma comercial, de inferior qualidade, assim mesma aproveitada em várias regiões do Oriente (PIO CORRÊA, 1978).

De acordo com COZZO (1956), a madeira é muito valiosa, não só por suas características decorativas, mas também porque se pode obter em grande volume e fornece tábuas de excelentes dimensões. É de cor castanho claro a rosado, com alburno demarcado por coloração mais clara. Semi pesada, semi dura e moderadamente homogênea, textura mediana e grã direita. Seu veteado aparece melhor nas faces radiais e tem origem na existência de grandes raios lenhosos; estes quando cortados produzem máculas ou manchas de contorno irregular e que refletem a luz com brilho dourado.

Ainda segundo o mesmo autor, a madeira é moderadamente resistente, elástica, flexível, de média duração quando exposta ao tempo. 
Inodora e insípida; de fácil trabalhabilidade, polimento e lixamento bons, permitindo a obtenção de superfícies lisas e brilhantes.

COZZO ressalta ainda que o acondicionamento e a secagem são comumente difíceis, uma vez que mostra excessiva variação interior, o que pode ser minimizado com o corte no inverno e a produção apenas de tábuas radiais, as quais podem liberar as tensões internas causadoras de variações.

Os anéis de crescimento são bem definidos, existindo porosidade circular, constituída por linhas concêntricas de poros grandes, rodeados de parênquima, que se alternam com outras linhas escuras de tecido escuro, nas quais existem poucos poros pequenos. Os raios são muito largos e altos. (COZZO, 1956).

CARVALHO (1982), realizou um estudo no Paraná e concluiu que essa espécie, por apresentar ótima forma e poucas ramificações laterais, além de um bom crescimento, é muito promissora para produção de biomassa em larga escala, fator de relevância na industrialização da madeira.

Segundo SANTOS (1987), a madeira presta-se especialmente para aduelas de pipas, forros de casa, mobílias, caixas e pirogravura, além de carpintaria em geral. Ainda para marcenaria de luxo, arborização de parques, sombra em pastagens e quebra vento em cafezais segundo um levantamento da COAMO (1978).

De acordo com COZZO (1956), a espécie é indicada para produção de móveis finos, artigos de adorno, pequenos móveis, revestimento de interiores, recipiente para líquidos, implementos náuticos (remo, por exemplo), tacos de golf e artigos domésticos. Na carpintaria rural é útil para cabos de ferramentas, "varas" de alambrado, portas, vigas, pisos, carroceria de veículos diversos, mesas, bancos, etc.

Segundo um estudo realizado por TOMASELLI \& SILVA (1996), a grevilea é uma espécie de rápido crescimento, e por apresentar uma massa específica básica média $\left(510 \mathrm{~kg} / \mathrm{m}^{3}\right)$ possui ampla gama de utilização na indústria de produtos de madeira sólida. No experimento 104 Rev. Ciência e Natura, Santa Maria, 20: 101 - 115 , 1998 
realizado a espécie apresentou rendimento de 54\% na produção de serrados (tábua verde), $24 \%$ na produção de lâminas, e na produção de faqueados $85 \%$ quando a tora foi convertida em blocos e $65 \%$ quando convertida em lâminas. Concluíram ainda que a espécie apresenta potencial bom para a produção de compensados de uso geral.

Assim, este trabalho visa caracterizar anatomicamente a madeira de Grevillea robusta A. Cunn, com o intuito de fornecer subsídios e informações para estudos posteriores.

\section{MATERIAL E MÉTODOS}

O material estudado consiste em 6 árvores de Grevillea robusta, provenientes de um plantio consorciado com café da Companhia Melhoramentos Norte do Paraná, localizado em Terra Boa, norte do Paraná. As mesmas foram coletadas aleatoriamente, sendo retirados dois discos por árvore, um na base e outro no topo.

As amostras de madeira destinadas à obtenção das seções histológicas do xilema foram retiradas aleatoriamente dentro dos discos, tomando-se o cuidado de separar os bloquinhos mais próximos da medula e os mais próximos da casca, e devidamente orientadas nos planos de corte transversal, longitudinal radial e longitudinal tangencial, sendo fervidos em água para amolecimento. As seções anatômicas foram feitas em micrótomo de deslizamento modelo Spencer $A O n^{\circ} 860$, com espessura variando de 20 a 25 micrômetros, conforme a dureza do material. Para o tingimento das seções utilizou-se o Método da Tripla Coloração, com Acridina Vermelha, Crisoidina e Azul de Astra, sendo posteriormente desidratadas em série alcoólica ascendente, colocadas em xilol e montadas entre lâmina e lamínula com Entellan.

A maceração dos tecidos componentes da madeira foi efetuada pelo Método de Jefrey, o qual consiste no desmembramento das estruturas através de uma solução aquosa de ácido crômico e ácido nítrico, 
ambos a 10\%, na proporção de 1:1. Utilizou-se safranina como corante, sendo posteriormente desidratados em série alcoólica ascendente, ficando conservadas em álcool absoluto. Foram confeccionadas lâminas temporárias, apenas com a finalidade de medição dos elementos.

Foram efetuadas observações e medições em número de 25 para as amostras mais próximas à medula e 25 para as mais próximas à casca, totalizando 50 por disco, para comprimento, diâmetro e espessura da parede das fibras; comprimento, diâmetro e espessura da parede dos elementos vasculares; poros $/ \mathrm{mm}^{2}$; altura e largura dos raios em micrômetros e em número de células; frequência dos raios $/ \mathrm{mm}$; além da porcentagem dos elementos constituintes do xilema secundário.

Tanto para as descrições microscópicas como para as mensurações dos elementos celulares individuais foram seguidas as normas da ABNT, com alterações introduzidas por MUÑIZ \& CORADIN (1991).

Os dados quantitativos dos caracteres anatômicos obtidos das medições foram processados em computador e obteve-se valores médios, máximos, mínimos e desvio padrão para cada característica estrutural. Para a confirmação da existência de diferenças entre os elementos da base e do topo, bem como dos próximos à casca e medula, realizou-se o teste de Tukey.

Para a ilustração do trabalho foram tomadas fotomicrografias em um fotomicroscópio Carl Zeiss do Laboratório de Anatomia da Madeira da Universidade Federal do Paraná . O filme empregado foi Kodak-Asa 100. Também foi realizada microscopia eletrônica de varredura, no Centro de Microscopia Eletrônica da UFPR, utilizando filme Vericrhome 120, fixador e papel revelador da Kodak.

\section{DESCRIÇÃO DA MADEIRA}

Características Macroscópicas: madeira moderadamente dura; cerne e alburno pouco distintos, o primeiro marrom claro a 
avermelhado, o segundo branco acinzentado; brilho moderado nos planos radial e tangencial devido às dimensões dos raios; textura média a grossa; grã direita a oblíqua nas faces tangenciais; cheiro e gosto imperceptíveis; camadas de crescimento pouco distintas a indistintas.

\section{Características Microscópicas:}

Anéis de Crescimento: pouco distintos, demarcados pela presença de zonas fibrosas irregularmente espaçadas.

Vasos: moderadamente visíveis a olho nu, solitários e múltiplos radiais e tangenciais, presença de racemiformes (Figura 1); porosidade difusa. Diâmetro tangencial variando de 50 - $124-210 \mu \mathrm{m}$ $(\mathrm{S}=49,5)$, paredes com espessura média de $6 \mu \mathrm{m}$; seção circular a oval; 3 a 30 poros $/ \mathrm{mm}^{2}$. Comprimento dos elementos vasculares variando de 100 220 - $400 \mu \mathrm{m}(S=57,6)$, com placas de perfuração simples (Figura 1) e apêndices curtos ocasionalmente presente em ambas as extremidades. Pontoações intervasculares alternas, de diâmetro pequeno, de forma circular e aberturas horizontais inclusas, às vezes coalescentes (Figura 2). Pontoações parênquimo-vasculares e raio-vasculares semelhantes às intervasculares. Estriações presentes em parte das paredes dos vasos, tilos ausentes.

Parênquima axial: visível a olho nu, paratraqueal vasicêntrico e confluente em faixas tangenciais, formando festões entre os raios (Figura 1), uma característica da família Proteaceae.

Parênquima radial: raios uni e multisseriados, os primeiros poucos, baixos, 2 a 20 células de altura, compostos por células procumbentes, usualmente de forma irregular. Os multisseriados são homogêneos a fracamente heterogêneos, com altura entre 14 - 68 - 121 células $(\mathrm{S}=36)$ e $600-1513,5-2730 \mu \mathrm{m}(\mathrm{S}=458)$; largura variando de 7 - 15 - 23 células $(S=4)$ e $90-236-390 \mu \mathrm{m}(S=56,5)$. Frequência por $\mathrm{mm}$ de $1 \mathrm{a}$ 5 , média de $2(S=0,74)$. 
Fibras: tecido fibroso abundante, fibras libriformes, não septadas, de seção poligonal. Pontoações simples a inconspicuamente areoladas na face radial. Comprimento 1050 - $1633-2300 \mu \mathrm{m}(\mathrm{S}=410)$, paredes espessas com $5-9-10 \mu \mathrm{m}$.

Outras características: máculas medulares, canais traumáticos e canais intercelulares radiais (Figura 2) ocasionalmente presentes.

\section{ANÁLISE DA ESTRUTURA DA MADEIRA}

\section{Porcentagem de Tecidos}

De acordo com a Figura 3, a porcentagem dos tecidos constituintes do xilema secundário encontrada mostra a grande quantidade de fibras existente (37\%) e que as células de reserva, parênquima axial e radial compõe $48 \%$ da estrutura e os vasos, $15 \%$. Estes dados foram obtidos através de uma média geral, não sendo separados de acordo com a posição uma vez que a variação foi insignificante. Com base nestes valores e nas definições dadas por BURGER \& RICHTER (1991), pode-se dizer que a resistência mecânica da madeira tende a ser média; que em relação à durabilidade natural, em virtude da presença de grande quantidade de células de reserva a mesma tende a ser baixa, e que a permeabilidade será alta em função da elevada proporção de parênquima associado com os vasos. COZZO (1956) comenta as mesmas propriedades citadas anteriormente.

As Figuras 4, 5 e 6 mostram a diferença existente entre a base e o topo, nas seis árvores amostradas, em relação ao diâmetro tangencial dos poros, comprimento dos elementos vasculares e comprimento das fibras, indicando que a primeira característica quase não apresenta variação nas diferentes posições da árvore, ocorrendo o inverso em relação ao comprimento dos elementos vasculares e das fibras, onde as 


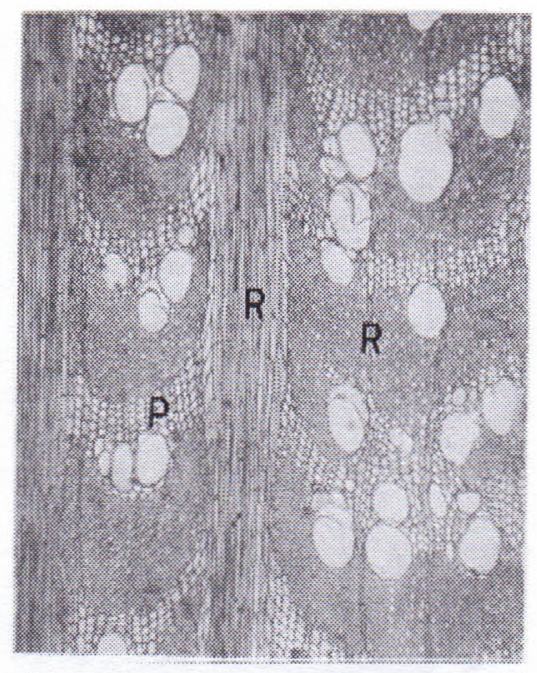

A

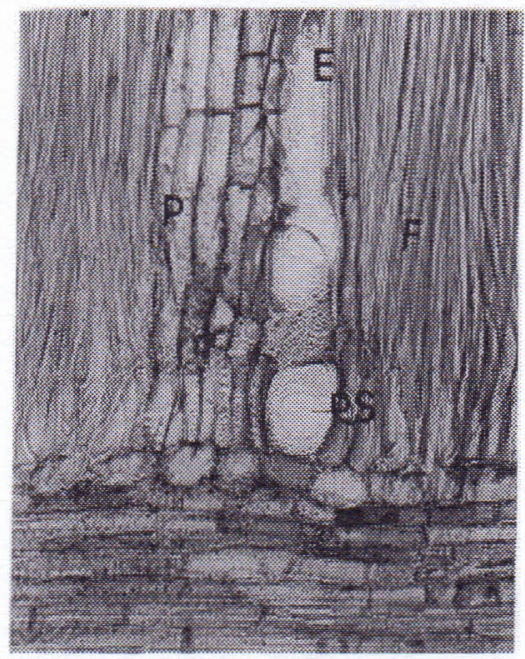

C

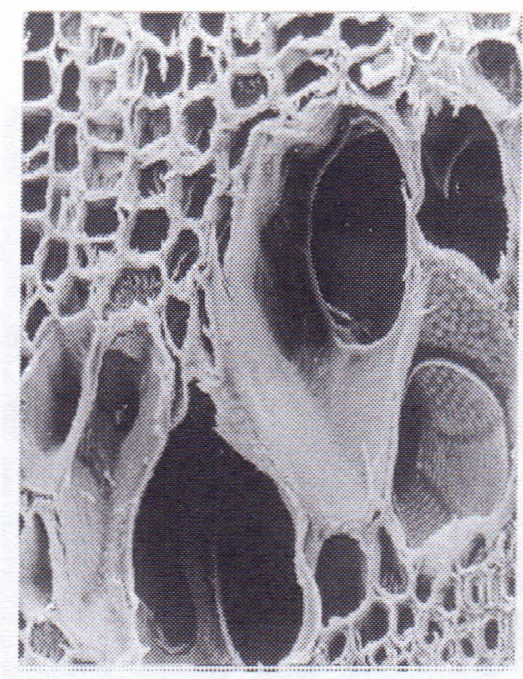

B

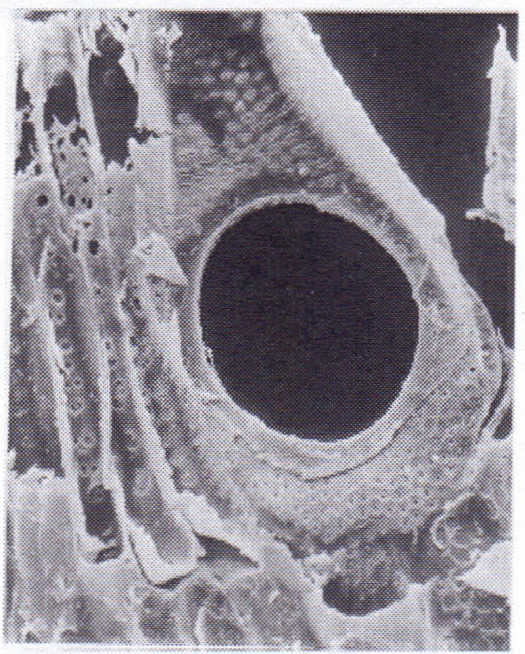

D

Figura 1: Fotomicrografias $(A, C)$ e fotografias em microscópio eletrônico de varredura (B, D): $A)$ Seção transversal: porosidade difusa, parênquima formando festões entre os raios $(P)$, raios uni e multisseriados $(R)$ (aumento 50x). B) Seção transversal: poros múltiplos (aumento 312x). C) Seção radial: placa de perfuração simples (PS), estriações nos vasos (E), parênquima $(P)$ e fibras $(F)($ aumento $200 x$ ). D) Seção radial: placa de perfuração simples (aumento 482x). 


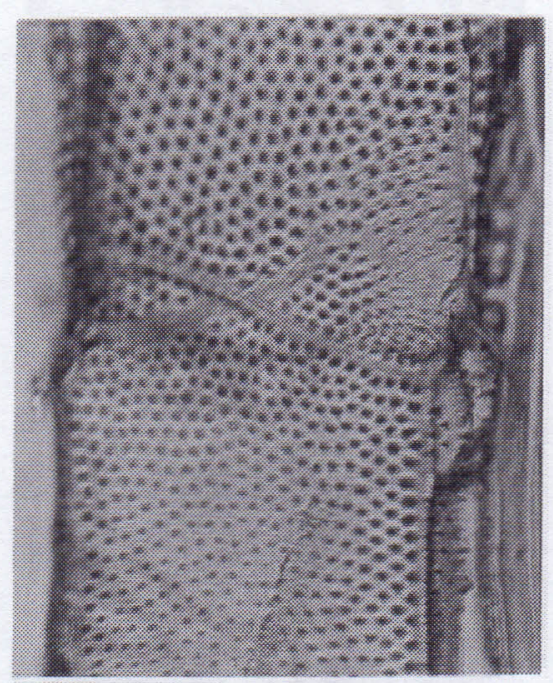

A

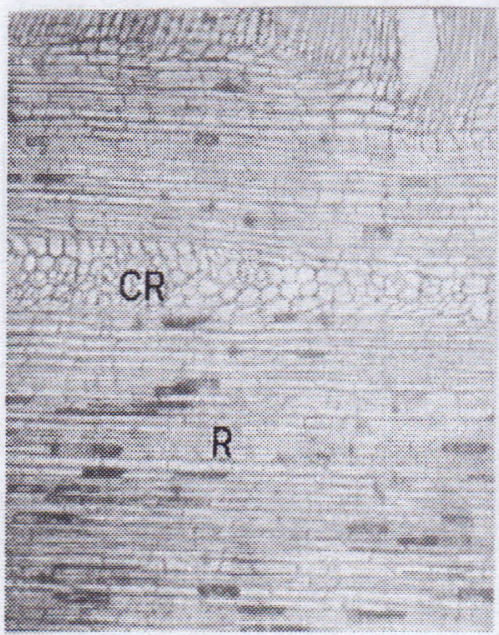

C

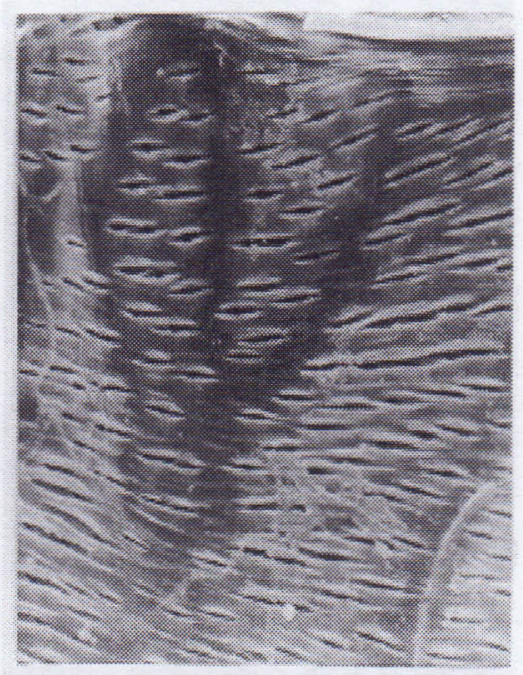

B

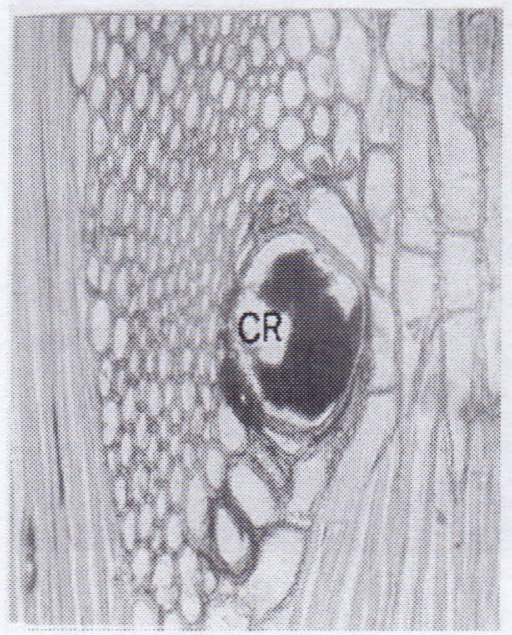

D

Figura 2: Fotomicrografias (A, C, D) e fotografia em microscópio eletrônico de varredura (B): A) Seção tangencial: pontoações intervasculares (aumento 625x). B) Seção tangencial: pontoações intervasculares com abertura inclusa (aumento 1050x). C) Seção radial: canal intercelular radial (CR), raio (R) (aumento 50x). D) Seção tangencial: canal intercelular radial (CR) (aumento 400x).

110 Rev. Ciência e Natura, Santa Maria, 20: 101 - 115 , 1998 
amostras provenientes do topo das árvores apresentaram valores $4 \%$ maiores. Esta tendência foi encontrada tanto na amostras próximas à casca quanto nas próximas à medula.

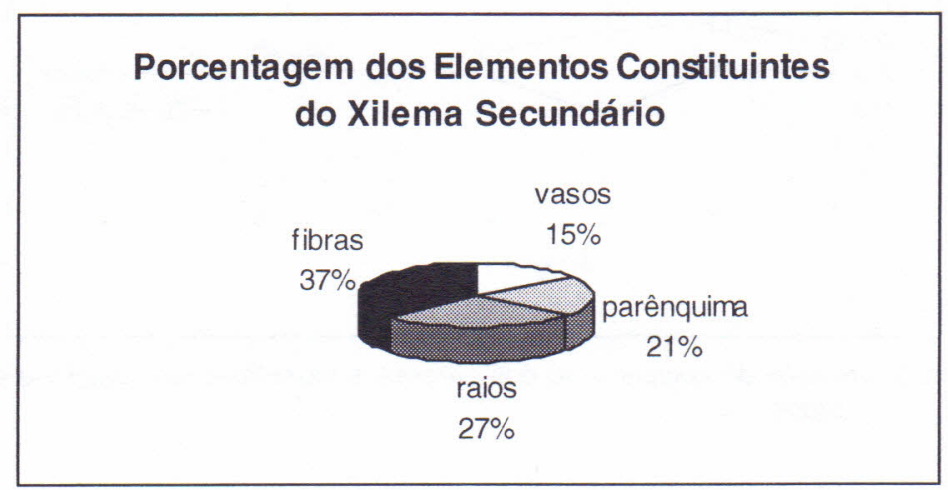

Figura 3: Elementos constituintes da madeira de Grevillea robusta A. Cunn.

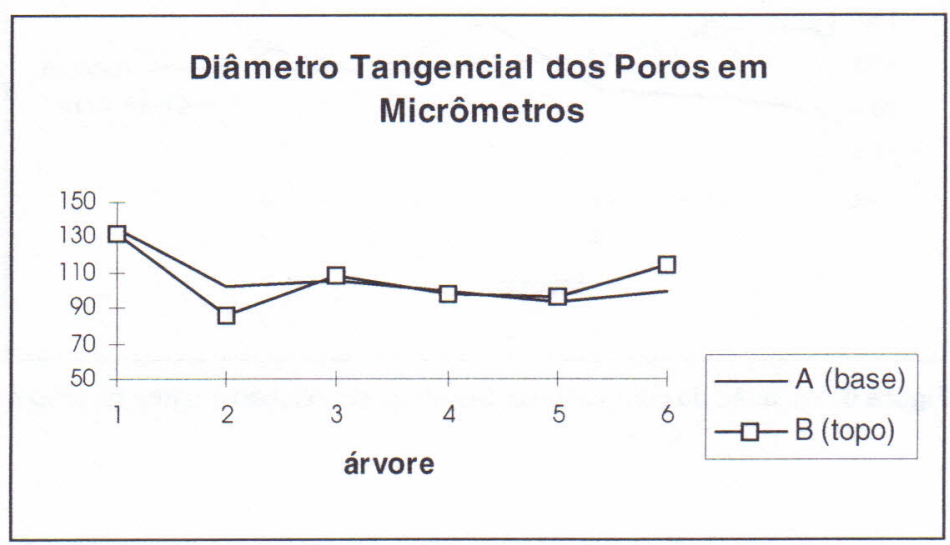

Figura 4: Variação do diâmetro dos poros em relação à altura na árvore. 


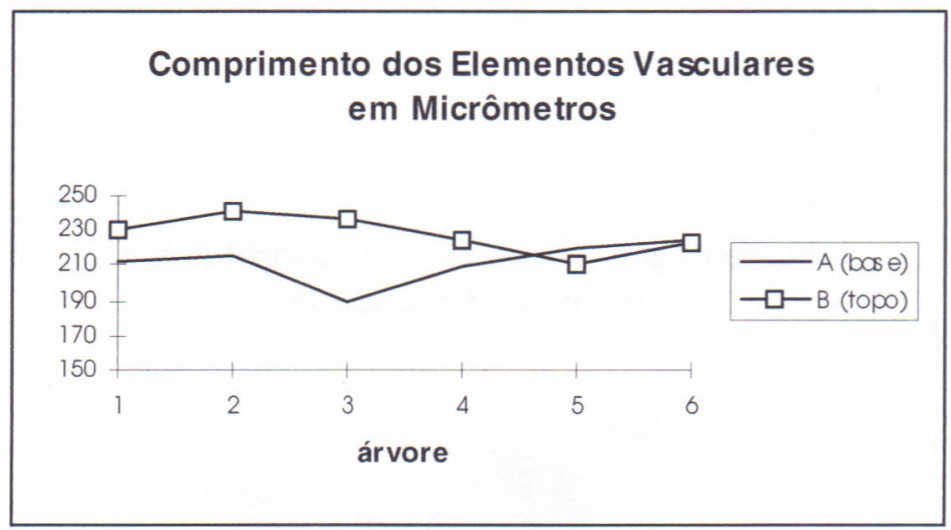

Figura 5: Variação do comprimento dos elementos vasculares em relação à altura na árvore.

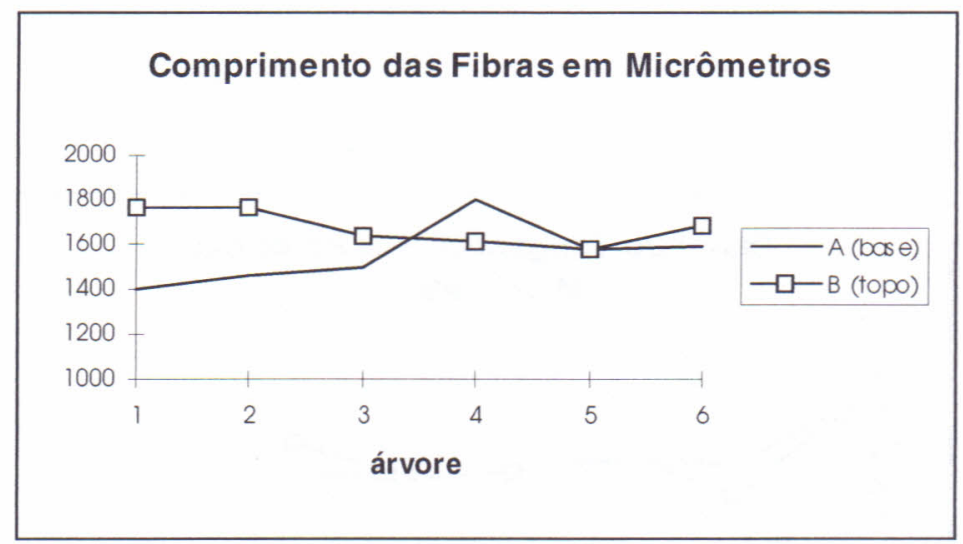

Figura 6: Variação do comprimento das fibras em relação à altura na árvore.

$\mathrm{Na}$ comparação entre as amostras próximas à casca e próximas à medula verificou-se que em relação ao diâmetro tangencial dos vasos, os valores foram $12 \%$ maiores no primeiro caso, e em relação à 
porcentagem dos elementos constituintes, a proporção de vasos foi $7 \%$ maior próximo à casca, a proporção de parênquima radial e axial permaneceu constante e a proporção de fibras esteve 3\% superior próximo à casca.

Em todas as amostras foi observado que os vasos são pequenos a médios, solitários e múltiplos radiais e tangenciais, caracteristicamente associados com faixas de parênquima e com eles formando festões entre os raios. Também verificou-se que as pontoações raio-vasculares e parênquimo-vasculares são similares às intervasculares, sendo ocasionalmente unilateralmente compostas. METCALFE \& CHALK (1965) também observaram as características acima.

A presença de raios de dois tipos, uni e multisseriados, bem como a frequência, largura e altura estão de acordo com o encontrado por COZZO (1956). METCALFE \& CHALK (1965) observaram ainda células de revestimento ocasionais, o que foi constatado na presença de raios fracamente heterogêneos.

Ainda observou-se a presença ocasional de canais intercelulares do tipo traumático, o que também é citado por METCALFE \& CHALK (1965), o qual observou ainda traqueídeos vasicêntricos.

\section{CONCLUSÕES}

A análise da estrutura anatômica da madeira de Grevillea robusta permite as seguintes conclusões:

- em algumas amostras existem máculas medulares ocasionais indicando que algumas árvores do povoamento sofreram danos físicos provavelmente ocasionados por intempéries ou pelo homem;

- a presença de raios uni e multisseriados, fracamente heterogêneos e tanto altos como largos demonstra que a espécie está numa fase intermediária de evolução; 
- a porosidade difusa, poros curtos e longos, com apêndices curtos em ambos os lados, espessamento espiralado em alguns, placas de perfuração simples, confirma a citação acima;

- o tipo de parênquima é característico da família, sendo que a porcentagem de tecido encontrada também está dentro do obtido para as proteáceas;

- a presença ocasional de canais intercelulares radiais está adequada com o citado em literatura;

- a variação encontrada entre os elementos próximos à medula e próximos à casca foi estatisticamente significante a nível de $1 \%$ de probabilidade, sendo que alguns elementos constituintes são maiores próximos à medula (por exemplo poros $/ \mathrm{mm}^{2}$ ) e outros à casca (por exemplo diâmetro tangencial dos poros), e alguns não apresentam variação, como é o caso da porcentagem de parênquima radial e tangencial, o que é ocasionado por diferentes estágios de crescimento da árvore;

- a variação dos elementos constituintes dentro de uma mesma árvore foi estudada, em relação à base e ao topo, em relação ao diâmetro tangencial dos poros, comprimento dos elementos vasculares e comprimento das fibras, indicando que as amostras provenientes do topo das árvores apresentaram valores $4 \%$ maiores.

\section{REFERÊNCIAS BIBLIOGRÁFICAS}

BURGER, L.M. \& RICHTER. Anatomia da madeira. São Paulo: Editora Nobel, 1991. 154p.

CARVALHO, P.E.R. Comportamento de essências florestais nativas e exóticas em dois locais do Paraná. Anais $4^{\circ}$ Congresso Florestal Brasileiro, Belo Horizonte, 1982. p.262-6. 
COAMO Espécies Florestais. 1978

COZZO, D. Como utilizar la madera de los arboles cultivados. Buenos Aires: Editorial Cosmopolitana, 1956. 222p.

METCALFE, C.R. \& CHALK, L. Anatomy of the dicotyledons - Vol 1. Oxford: Claredon Press, 1965. 724p.

MUÑIZ, G.I.B. \& CORADIN, V.R. Normas de procedimentos em estudos de anatomia da madeira: I-Angiospermae, II Gimnospermae. Brasília: Laboratório de Produtos Florestais, Série Técnica 15, 1991.

PIO CORREA, M. Dicionário das plantas úteis do Brasil - vol III. Rio de Janeiro: IBDF, 1978.

SANTOS, E. Nossas madeiras. Belo Horizonte: Ed. Itatiaia Ltda, 1987. $313 p$.

TOMASELLI, I.\& SILVA, L.B.X. Grevillea, cinamomo e outras madeiras, produção e mercado. Anais IV SEMADER, Curitiba, 1996. p.5-15. 
116 Rev. Ciência e Natura, Santa Maria, 20: 101 - 115 , 1998 